Psychological Medicine, 1979, 9, 5-8

Printed in Great Britain

\title{
EDITORIAL
}

\section{The doctors, their patients and their care: Balint reassessed ${ }^{1}$}

Recent articles and correspondence in the Journal of the Royal College of General Practitioners on the subject of Michael Balint, his work and influence, and the role of psychotherapy in general practice are the occasion of this commentary. My title refers to and paraphrases the subject of these exchanges, The Doctor, his Patient, and the Illness (Balint, 1957). Their focus, it seems to me, is a return to unity, especially the unity of patient care, and a return to a science of the mind, not without humane philosophy but without ideology. Such a development is made possible by modern advances in the understanding and treatment of mental illness.

The published exchanges in the Journal of the Royal College of General Practitioners began in the October 1977 issue with an article entitled 'Balint reassessed: The Doctor, his Patient and the Illness: a reappraisal' by Peter Sowerby (1977). Sowerby's own summary is a clear exposition of his point of view and may be quoted in full:

Psychoanalytical theories seek to explain human behaviour. I believe that they are not scientific, whereas it appears that Balint thought they were. I suggest instead that they are better regarded as myths and part of an artistic discipline. Whereas most of the problems brought by patients to general practitioners can be understood in scientific terms, others can be understood only in artistic terms.

These two terms reflect fundamentally different kinds of problems, and different language must be used to discuss them. Neither the two sets of terms nor the two kinds of problems can be confused without giving rise to error. I argue that Michael Balint came to a false conclusion about the nature of a general practitioner's task, about the way the problems posed by his difficult patients may be identified, and about some of the training doctors should receive. Balint's main contribution remains. He showed us that scientific skills alone are not enough if we are to understand our patients fully. He also showed us how a descriptive science of human behaviour in the consulting room was possible.

To these insights must be added new understanding. Popper (1963) has provided us with a clear line of demarcation between science and the rest of our knowledge. This idea suggests that general practitioners should reaffirm the importance to them of the intellectual discipline of science. If they wish their understanding and practice to be comprehensive they must also affirm the importance of the arts. What they must not do is to confuse one with the other.

Sowerby's paper pays tribute to the effect of the Balint seminars and the publication of his book in 1957. This he describes as a 'seminal event' which created new insights into the work of general practitioners and raised new hopes for the development of their practice. He implies that at the time Balint's work gave self-confidence to many GPs and helped to evolve a specific identity for their new College. He disputes, however, the validity of the psychoanalytical approach to the problems of general practice. (To avoid any confusion of terminology, the 'psychotherapy' which Balint advocated for general practice was, in his own description, 'applied psychoanalysis'. Today the term is often loosely applied to the description of a doctor's understanding and support of a patient.)

Sowerby criticizes Balint's observation that 'the more one learns of the problems of general practice the more impressed one becomes with the immense need for psychotherapy' and refers to the surprising conclusion 'that general practice is primarily concerned with psychological problems'. He questions corollaries of this view, namely, 'that psychological illness should not be diagnosed by exclusion'; that the continuity of the relationship existing in general practice makes 'a unique kind of psychotherapy' possible; that 'a unique relationship establishes itself between a general practitioner and... his patients'; and that skill in this aspect of work requires training and a 'limited though considerable change in the doctor's personality'.

Developing from Popper the argument that scientific propositions must be able to be confirmed

\footnotetext{
- Address for correspondence: Dr T. A. Madden, Room 740, Professional Building, Rush Presbyterian St Luke's Medical Center, 1725 West Harrison Street, Chicago, Illinois 60612, USA.
} 
or refuted by observation, Sowerby holds with others that psychoanalysis is scientific in its descriptions, but not in its explanations which are irrefutable. This is not, in his view, to deny them any value at all: they are useful in the way that myths have been useful to man.

On the question of the 'unique relationship', Sowerby is refreshingly blunt: 'there is, after all, nothing unique about the doctor-patient relationship'. The human relations of medicine, in my own view, are of a kind with other human relationships; there should be no human separation in the doctor-patient relationship which is based upon the skill, special knowledge and 'advantage' of the professional protagonist. By contrast, it is basic to the psychoanalytical view that in the therapeutic relationship both patient and doctor gain from such a separation between them, from the fact that the doctor is a special person. Psychotherapy has, after all, been defined as 'a form of treatment for problems of an emotional nature in which a trained person deliberately establishes a professional relationship with a patient with the object of removing, modifying or retarding existing symptoms, of mediating disturbed patterns of behaviour and of promoting positive personality growth and development' (Wolberg, 1967).

At the clinical level Sowerby criticizes Balint's handling of some of the cases described in his writings and his attitude to certain major psychiatric illnesses. Thus, in more than half of the cases described, he considers that the possibility of a depressive illness was ignored and, in general, depression was viewed as a symptom rather than an illness. Indeed, if psychological illness is met in the consulting room as 'undifferentiated illness which presents as a disorder of behaviour' then, Sowerby argues, diagnosis is only possible by exclusion, as with undifferentiated physical illness such as a PUO. Such an approach to diagnosis is particularly important for the general practitioner who, on the one hand, does not know that the patient with depressed mood, energy and drive has not a concealed carcinoma and, on the other, must include the possibility of depressive illness in the differential diagnosis.

Sowerby also indicates that among Balint's cases the second largest group was composed of those with 'fixed neuroses of poor prognosis no matter how much help they had received'. Here it is relevant to recall a question posed by Hicks about social work: "how does the casework social worker balance the time devoted to serious but hopeless cases for which it could be judged little was achievable against the time devoted to less serious cases where something worthwhile could be achieved?' (Hicks, 1976). In the sphere of psychopathology, the question is applicable to the work of the general practitioner with this group of patients. The total volume of the doctor's work, his duty to many individuals and to other essential tasks in patient care, education and management - all of these raise important considerations of fairness and effectiveness - for while the family doctor may see the bulk of psychiatric illness in the community, most would not consider that general practice is 'primarily concerned with psychological problems'.

Finally, Sowerby implicitly criticizes the Royal College of General Practitioners for promoting a system of training general practitioners by case discussion for the tasks assigned by Balint. He points out that what Balint himself considered unsuitable for some is 'now promoted as a method suitable for all' and indicative of the 'qualities necessary for general practice'.

Sowerby's standpoint has been challenged by John Williamson (1978) who situates Balint in his own time and points out that much of what we now know about depression was not appreciated in the 1950s. Williamson contends that Balint was trying to show the relevance of 'models' other than the medical; to demonstrate that 'psychological problems are often manifested through physical means and that even physical disease has its own psychological consequences which demand particular attention'; that the physician 'is not a neutral uninvolved observer, the patient is not a goldfish in a bowl'; and that 'to take advantage of the possibilities of general practice requires an appropriate form of teaching'. He concludes his article thus: 'Balint's aim was to improve general practice. His fundamental point was not the importance of psychological aspects of life or illness but the interactive nature of the medical consultation. His message is as relevant today as it was when he first expressed it.' While I doubt the validity of this conclusion, many of the observations seem fundamental to daily practice. Nevertheless, the case for psychotherapy as a part of that practice is not, I feel, made. 
In the correspondence which has followed Sowerby's reappraisal, a number of important points have been made, including: the unity of the various elements in the patient's illness; Balint's undue stress on the diagnostic importance of the communication between patient and doctor (the interview); criticism of Balint-type seminars and of judgements of poor performance in them as evidence of emotional immaturity; the importance of cultural factors in communication with patients, for example knowledge of the vernacular of a district; the need to study the whole patient; and the pragmatic, rather than scientific, essence of general practice. Contributors on both sides are equally concerned about the well-being of their patients with emotional and psychiatric problems. It is not good-will which divides them. All are motivated by a human concern for and approach to the patient; none denies the therapeutic aspect of the doctor-patient relationship. This is an encouraging aspect of a debate which has nonetheless seemed to remain in the past rather than to focus upon present challenge, although Sowerby originally indicated the significance of the topic for future policy.

There, for the moment, the debate rests. Since the publication of the work of Shepherd et al. (1966), it has no longer been possible to deny that the bulk of psychiatric illness in the community is met and 'handled' in general practice; and that the work of the GP includes the continuing care of serious mental illness, for which hospital involvement is episodic. Recently, Hassall \& Stillwell (1977) have shown that, in a general practice register of about 14000 patients, the 'listed' psychiatric patients consulted with the GP just over twice as often as (and required more time than) a control group, and that this was true even of patients at the time in receipt of help from the specialist psychiatric services. Considerations of custom, work-load, cost and community interest make it likely that this will continue to be the pattern in the United Kingdom. Yet, if we question how much we in general practice do for many of our psychiatric patients, the results are not impressive, whatever our orientation, in whatever way we view and describe what we observe. A self-critical attitude is desirable and necessary.

Accepting this pattern, what considerations ought we to have in mind in relation to the future cooperation of GPs and specialists? And what is at present missing from this cooperation from the point of view of GPs and their patients?

I believe that we must oppose ideology in mental illness, whether it is the ideology which treats the politically disaffected as in need of drug therapy and confinement or the more clearly humane concepts of the Freudians and post-Freudians with their strangely antique glossary. If psychotherapy implies no more than steady support, a sympathetic and understanding attitude, a sophisticated understanding of the complexities of human behaviour and at best a certain wisdom about life, then clearly this is needed in all patient care. But has it a place in future general or hospital practice in the sense that it is defined by the psychoanalytical school with its special lights? Psychotherapy aims to restore the normal milieu, yet its classical technique does not favour immediate gain and may favour adjustment to chronicity. In practical terms, if it is as vital as Balint suggested at the GP and community level, how has it come about that it is almost unobtainable at the expert level, and then only after intensive screening of the potential case as suitable for treatment? This surely implies, in the view of experts, a very limited and selective usefulness. Where it is available, it is, in effect, most often in the diluted form of group therapy. The group, whatever conflicting merits are claimed for its various rites and practices by different authorities, is essentially different from the classical therapeutic relationship, a continuing relationship between two individuals. It is a way of sharing the expert; and probably owes its popularity to this economy above all. It also dilutes the effect of confrontation and may work well simply in its function as a group for this very reason. It may answer for the therapist a question which the GP isolated with his patient may not be able to answer: Quis custodiet custodios? Thus, the group lessens the doctor's responsibility to a volume of human woes; and involves the patients in their own progress towards health. In the absence of 'community', it creates a coping mechanism for the patient, a ready-made social network.

While some patients of the general practitioner will need continuous and understanding support, practical help and explanation of their difficulties, in terms of individual psychotherapy (as defined), 
I can see no case for the GP to offer a service that the specialist does not now offer. I see no reason in contemporary practice for GPs to be the last practitioners, and their consulting rooms the last outposts of the golden art; and to meet the next suggestion on the conveyor belt, I do not think that this should become by delegation the task of social workers in the group practice or health centre, even if their training and background still contain many vestiges of Freudianism in its case-work approach.

The answer surely lies elsewhere. If it is intended more and more to keep the patient in the community, or to return him to the community, the consultant can no longer follow him only by means of out-patient appointments. If prevention means anything, it implies specialist involvement in the community, helping to prevent admissions, to prevent relapse, to prevent suicide, to foresee and help handle school and educational problems, to reinforce 'coping mechanisms', to help families via the various social agencies at the disposal of hospital psychiatry, to consider planning needs. It means helping the helpers. All of this implies a greater and closer cooperation of hospital and community doctors than ever before, and if this involves some reorganization of the work-day of both, to see certain patients together, to discuss management, then this should be done.

In general, the clear aim of both ought to be the maximal rehabilitation of the patient towards independence, towards autonomy within the supporting family, group, community, an aim rarely achieved in the chronic case; and, it must be said, rarely considered in most cases. If a return to full social function is the measure of this and occupation a vital determinant, it is admittedly difficult to achieve in a society which tolerates unemployment to such a degree as at present. If the alienist is not to be one who sets people apart, psychiatry must become, in Sir Aubrey Lewis's words, 'a branch of social medicine'.

T. A. MADDEN

\section{REFERENCES}

Balint, M. (1957). The Doctor, his Patient and the Illness. Pitman Medical: London.

Hassall, C. \& Stilwell, J. A. (1977). Psychiatry in general practice. Journal of the Royal College of General Practitioners 27, 605-608.

Hicks, D. (1976). Primary Health Care p. 391. Department of Health and Social Security. HMSO: London.

Popper, K. R. (1963). Conjectures and Refutations. Routledge \& Kegan Paul: London.
Shepherd, M., Cooper, B., Brown, A. C. \& Kalton, G. W. (1966). Psychiatric Illness in General Practice. Oxford University Press: London.

Sowerby, P. (1977). Balint reassessed. Journal of the Royal College of General Practitioners 27, 583--589.

Williamson, J. (1978). Balint's contribution to general practice. Journal of the Royal College of General Practitioners 28, 207-209.

Wolberg, L. (1967). The Technique of Psychotherapy. Grune and Stratton: New York. 